\title{
Fetomaternal outcomes in pregnancy complicated by epilepsy- a retrospective study
}

\author{
Chithra R.*, Siddhi Shree Dixit, Janu M. K., Sandhya
}

Department of Obstetrics and Gynaecology, Amrita Institute of Medical Sciences, Cochin, Kerala, India

Received: 01 October 2021

Accepted: 08 November 2021

*Correspondence:

Dr. Chithra R.,

E-mail: Chithrar01@gmail.com

Copyright: (c) the author(s), publisher and licensee Medip Academy. This is an open-access article distributed under the terms of the Creative Commons Attribution Non-Commercial License, which permits unrestricted non-commercial use, distribution, and reproduction in any medium, provided the original work is properly cited.

\begin{abstract}
Background: This study is conducted to find out possible course and complications of epilepsy and its treatment in mother and fetus as many women will be anxious regarding this high-risk condition.

Methods: This is a retrospective study conducted in department of obstetrics and gynaecology, AIMS Kochi from 2012-2019. Out of a total of 7045 deliveries during that period, we identified 64 patients with epilepsy complicating pregnancy. Antepartum, intrapartum and postpartum details of 57 patients whose data was available in electronic medical records was collected and analysed using SPSS 17 software.

Results: In this study we noted that the incidence of epilepsy was $0.009 \%$. the $50 \%$ of patients were in $25-30$ years age group. More than $98 \%$ were on long term antiepileptic drugs. Majority were on monotherapy, most commonly on leviteracetam and were well controlled with monotherapy. The $38.5 \%$ had recurrence of seizures during pregnancy, mostly in latter half of pregnancy. Patients with seizure free interval of 9 months prior to pregnancy did not have any further epilepsy episodes. The incidence of other medical and obstetric complications was found to be similar to general population. There was $10 \%$ incidence of IUGR and fetal anomaly.

Conclusions: The seizures were well controlled with monotherapy and we found that generally pregnancy and delivery is well tolerated and overall neonatal outcomes were good.
\end{abstract}

Keywords: Epilepsy, Seizure, pregnancy, Leviteracetam

\section{INTRODUCTION}

Epilepsy is the recurrent unprovoked seizures resulting from excess neuronal discharge. It is the most common neurological condition in pregnancy which needs medical treatment. ${ }^{1}$ Since $40 \%$ of women are in the reproductive age it is fairly common to see epileptic patients embarking on pregnancy. Although most of the pregnancies progress without complications it is considered as a high-risk pregnancy. Recent advances in antiepileptic medications have helped to limit the seizure frequency and duration. But still, it is not uncommon to see severe forms of epilepsy like status epilepticus which can cause much maternal morbidity. The risk of fetal complications is twice common in patients with epilepsy than in general populations-may be because of use of anti-epileptic drugs or direct effect of epilepsy causing hypoxic insult to placenta. $^{2}$

There are significant variations in the reported fetomaternal complications across various populations we conducted this study to analyze the outcomes of pregnancy complicated by epilepsy in our institution.

\section{METHODS}

This study was conducted in the department of obstetrics and gynecology, Amrita institute of medical sciences, Kochi from 2012 to 2019. 
It is a retrospective descriptive study in which the data of all booked antenatal patients diagnosed with epilepsy was collected from the labor records and electronic medical records.

Out of the 7045 deliveries during these periods we identified 64 patients with epilepsy. Since the follow up data was not available for 7 patients they were excluded from the study. All these patients were taking $5 \mathrm{mg}$ if folic acid and neurology opinion.

All patients underwent anomaly scan and growth scan and regular antenatal checkup.

The details of these 57 patients with epilepsy-like age, parity, type, years of seizure medications, seizure free interval before pregnancy, drugs used in pregnancy (monotherapy or polytherapy), seizure episode during pregnancy in each trimester, coexisting medical disorders like gestational diabetes, pregnancy induced hypertension and obstetric complications like preterm labor, PPROM, antepartum hemorrhage, mode of delivery, fetal outcomes like anomalies, birth weight; were collected.

All babies were given injection vitamin K IM at birth as part of routine IAP protocol and also started breastfeeding soon after birth.

Both maternal variable and fetal variable were presented in frequency and percentage using SPSS version 17.

\section{RESULTS}

Out of the total 7044 deliveries over 8 years (2012-2019) in our institution we identified 64 patients with epilepsy complicating pregnancy thus giving a very low incidence (0.009) (Figure 1).

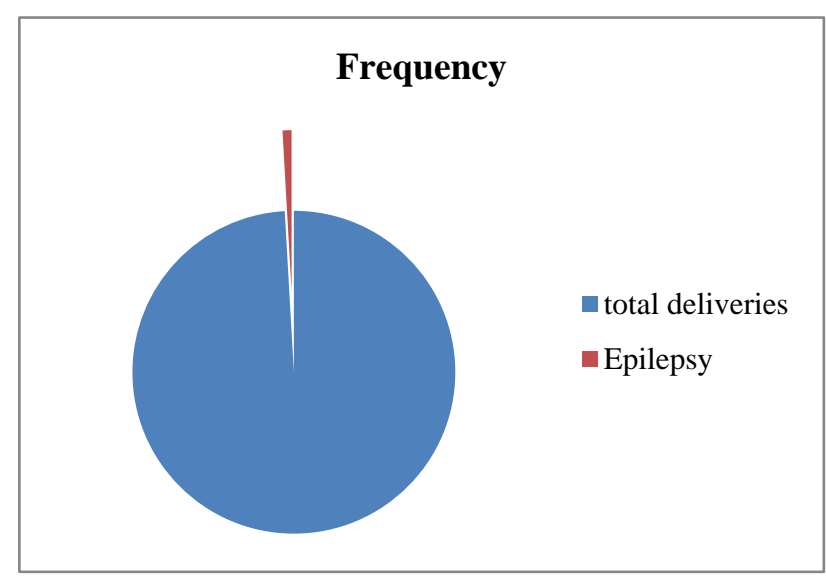

Figure 1: Frequency.

Out of 57 patients, majority were in 25-29-year age group $(50.9 \%), 59 \%$ were multigravidas and $47.4 \%$ patients were on AED for 10-20 years. Only one patient was not on any AED as her last seizure episodes was 7 years back, hence the drug was withdrawn (Table 1).
Table 1: Sociodemographic analysis.

\begin{tabular}{|lll|}
\hline Variables & Frequency & $\begin{array}{l}\text { Percentage } \\
(\%)\end{array}$ \\
\hline Age (Years) & & \\
\hline $18-24$ & 14 & 24.6 \\
\hline $25-29$ & 29 & 50.9 \\
\hline $30-35$ & 11 & 19.3 \\
\hline$>35$ & 3 & 5.3 \\
\hline Parity & & \\
\hline Primi & 23 & 40.4 \\
\hline Multi & 34 & 59.6 \\
\hline
\end{tabular}

Looking into the type of seizures it was noted that $77 \%$ patient had generalized tonic clonic seizure (44/57), $18 \%$ were diagnosed with myoclonic seizures, 2 cases $(3.5 \%)$ were of complex partial seizures and status epilepticus each.

Of the 57 patients only $26.3 \%$ (15/57) had received multiple medications for seizure control. In majority $(77.7 \%)$ were controlled with single AED like leviteracetam (49\%), benzodiazepine (26\%) and other drugs like topiramate (17\%).

Table 2: Epilepsy characteristics.

\begin{tabular}{|c|c|c|}
\hline Variables & Frequency & Percentage $(\%)$ \\
\hline \multicolumn{3}{|c|}{ Duration of seizures medications (Years) } \\
\hline$<10$ & 20 & 35.1 \\
\hline $10-20$ & 27 & 47.4 \\
\hline 20 & 9 & 15.8 \\
\hline No AED & 1 & 1.8 \\
\hline \multicolumn{3}{|l|}{ Type of seizures } \\
\hline GTCS & 44 & 77.8 \\
\hline Myoclonic & 1 & 1.8 \\
\hline Complex partial & 2 & 3.5 \\
\hline Status epilepticus & 2 & 3.5 \\
\hline Others & 8 & 14 \\
\hline \multicolumn{3}{|c|}{ Seizure free interval prior to pregnancy (years) } \\
\hline$<1$ & 22 & 38.5 \\
\hline$>1$ & 28 & 49.1 \\
\hline Not available & 7 & 12.4 \\
\hline
\end{tabular}

During the antenatal period 22 patients (38\%) had seizure episodes with comparable incidence in all three trimesters6 in $1^{\text {st }}$ trimester $(24 \%), 8$ each in $2^{\text {nd }}$ and $3^{\text {rd }}$ trimester $(36 \%$ each). We had one patient on polytherapy who had multiple uncontrolled seizures in all 3 trimesters with cause for same not identified and another patient who was on monotherapy had seizures in $2^{\text {nd }}$ and $3^{\text {rd }}$ trimester. The seizures subsided spontaneously postpartum after altering the dose of drug. 2 patients had intrapartum seizures and none happened in postpartum.

Of the patients who had seizures during the antenatal period $17.5 \%$ patients needed revision and hiking antiepileptic medications (Table 3). 
Table 3: Epilepsy characteristics in pregnancy.

\begin{tabular}{|lll|}
\hline Variables & Frequency & $\begin{array}{l}\text { Percentage } \\
(\%)\end{array}$ \\
\hline Drug treatment & & \\
\hline No drugs & 1 & 1.7 \\
\hline Monotherapy & 41 & 71.9 \\
\hline Levipil & 20 & 48.7 \\
\hline Benzodiazepines & 10 & 24.3 \\
\hline Carbamazepine & 4 & 9 \\
\hline $\begin{array}{l}\text { Others (like divalproex, } \\
\text { lamtorigine) }\end{array}$ & 7 & 17 \\
\hline Polytherapy & 15 & 26.3 \\
\hline Incidence of seizures in & pregnancy & \\
\hline Antepartum & 22 & 38.5 \\
\hline $1^{\text {st }}$ trimester & 6 & 27 \\
\hline $2^{\text {nd }}$ trimester & 8 & 36 \\
\hline $3^{\text {rd }}$ trimester & 8 & 36 \\
\hline All 3 trimesters & 1 & \\
\hline Intrapartum & 2 & 3 \\
\hline Postpartum & 0 & \\
\hline Pregnancy co-morbidities & 7 & 12.2 \\
\hline GDM & 4 & 7 \\
\hline PIH & 3 & 5 \\
\hline Change in dose/medications & \\
\hline Needed & 10 & 17.5 \\
\hline Not needed & 47 & \\
\hline
\end{tabular}

On analysis of maternal data, 3 patients developed pregnancy induced hypertension and 4 developed GDM. None of the patients had obstetric complications like antepartum hemorrhage, PPROM or stillbirth.

Over a half $(54 \%)$ of patient went for cesarean section because of various indication, most common being previous LSCS. The $84.3 \%$ were term deliveries while $15 \%$ were preterm deliveries.

Table 4: Fetal characteristics.

\begin{tabular}{|c|c|c|}
\hline Variables & Frequency & $\begin{array}{l}\text { Percentage } \\
\text { (\%) }\end{array}$ \\
\hline Congenital anomalies & $6 / 57$ & 10.52 \\
\hline IUGR & $7 / 57$ & 10 \\
\hline \multicolumn{3}{|c|}{ Gestational age at delivery } \\
\hline Pre term & 9 & 15.7 \\
\hline Term & 48 & 84.3 \\
\hline \multicolumn{3}{|l|}{ Mode of delivery } \\
\hline Normal & 26 & 45.6 \\
\hline LSCS & 31 & 54.4 \\
\hline \multicolumn{3}{|l|}{ Sex of the baby } \\
\hline Male & 35 & 61.4 \\
\hline Female & 22 & 38.6 \\
\hline \multicolumn{3}{|l|}{ Birth weight $(\mathbf{k g})$} \\
\hline$<2$ & 6 & 10.5 \\
\hline $2-2.5$ & 7 & 12.3 \\
\hline$>2.5$ & 44 & 71.2 \\
\hline
\end{tabular}

Out of 57 babies born 35 were males $(61 \%)$ and 22 were females. Majority $71.2 \%$ weighted average size of more than $2.5 \mathrm{~kg}$ while $10.5 \%$ were less than $2 \mathrm{~kg}$ (Table 4).

\section{DISCUSSION}

The 2.5 million Women in India suffer from epilepsy and $25 \%$ are in reproductive age group. Hence, addressing epilepsy in pregnancy is important.

The review of literature suggested preference of monotherapy over polytherapy during pregnancy. ${ }^{3}$ This is due to decreased risk of side effects and congenital anomalies due to synergistic effect of both the drugs. Even in our study, majority (77\%) were well controlled with monotherapy with drugs like leviteracetam, benzodiazepines. Polytherapy was resorted to only when there was failure of monotherapy at maximum permissible doses.

As per study by Robinson et al epilepsy has been associated with increased rates of cesarean section although the indication is not clear. Epilepsy itself is not an indication for cesarean section. ${ }^{4}$ The study consisted of $59 \%$ multigravidas and the rate of cesarean delivery in our study also of almost 54\%. The most common indication identified was previous cesarean with mobile head.

There is insufficient evidence of change in frequency of seizure episodes during pregnancy, as per American association of neurology, however Monead study stated that women who had a 9 month seizure free interval prior to pregnancy were less likely to have seizure episodes during pregnancy. ${ }^{5}$ Recent study showed, use of leviteracetam is associated with increased seizure free interval and better outcomes while lamotrigine and carbamazepine had similar results. ${ }^{6}$ In our study, majority of the patients $(49.1 \%)$ had seizure free period for more than 1 year prior to pregnancy and had hence had seizure free antenatal period.

The study of neurological diseases in pregnancy stated incidence of intrapartum seizure to be around $3-4 \% .^{7}$ In our study, we had 2 patients who had intrapartum seizures $(3 \%)$. Both were managed with IV leviteracetam.

There was one patient who was on polytherapy and had multiple episodes of epilepsy in ante partum and intrapartum period. This may be due to non-adherence to antiepileptic medications. One patient had multiple seizure episodes in second and third trimester; this could be due to change in therapeutic levels of leviteracetam in pregnancy, which ideally needs to be monitored as seen in study by Mahajan et al. ${ }^{8}$ However, RCOG does not currently recommend routine serum antiepileptic drug monitoring because of lack of its evidence on control of seizures. ${ }^{7}$

In previous studies like by Goel et al there was $24.3 \%$ incidence of PIH and 2.7\% incidence of GDM with epilepsy. ${ }^{9}$ Overall it has been reported that there is higher 
incidence of preeclampsia in patients with epilepsy complicating pregnancy especially on lamotrigine and carbamazepine. ${ }^{10}$ In our study, though the incidence of GDM was comparable to around 7\%; we got a lower incidence of PIH of around 5\% only. It could be related to use of leviteracetam; however, there is no proven study.

Due to increase in clearance rate of drugs during pregnancy, there is increased need for changing drug dosage and opting for higher doses. Almost $45 \%$ of patients needed change in drug dosage in our study.

Postpartum, risk of epilepsy is $1-2 \%$ but in our study no incidence of postpartum seizure was noted. ${ }^{7}$ This may be due to strict adherence to the antiepileptic medications.

Major malformations have been associated with use of valproate as a monotherapy or polytherapy so should be avoided. Antiepileptic like lamotrigine and levetiracetam even in combination are equivalent to monotherapy in safety. Among newer drugs, lamotrigine is safest during pregnancy though when compared to general population still higher risk of congenital malformations is there. Topiramate has intermediate risk of malformations with facial/palate cleft. Folic acid supplementation is recommended preconceptionally and during pregnancy at a minimum dose of $0.4 \mathrm{mg} /$ day ( $4 \mathrm{mg} /$ day if family history of neural tube defect, or on valproic acid, carbamazepine, or gabapentin). ${ }^{5}$

Epilepsy itself does not significantly increase risk of major congenital malformation. It is noted that risk of congenital malformation in women taking antiepileptic drug is $10 \%$ compared to general population. ${ }^{11}$ In our study, congenital anomalies were seen in $10.5 \%$ of the study group most of which were correctable cardiac anomalies like SVT, VSD.

As per previous studies, there is conflicting data on evidence of preterm delivery and SGA foetuses among women on antiepileptic and those without. In case of preterm deliveries, the cause has been attributed to seizure itself. $^{12}$ There is twofold increase in SGA babies amongst women on antiepileptic drugs compared to those not on any drugs. ${ }^{13}$ In our study we had $10 \%$ babies with growth restriction and low birth weight.

\section{Limitations}

In this retrospective study, data was collected from hospital records, hence few of the data was missing. There was loss to follow up and majority of patients studied in this were multigravidas. Because of small number of cases spread over a long period the effect of antiepileptic drugs could not be evaluated individually. Cases were managed by different consultants resulting in non-uniform protocols. There was a lack of other neonatal data like duration of NICU stay, management protocols and long term follow up. Hence targeted additional prospective study is needed. Despite these limitations we believe it will be useful for clinicians to counsel their patients about the prospective overall outcomes and management.

\section{CONCLUSION}

Pregnancy complicated by epilepsy is definitely a highrisk condition that needs multidisciplinary and careful management. Pre-conceptional counselling is very important in such patients and they should be counselled about optimising the antiepileptic medications, importance of compliance and adhering to follow up to see for change of dose. Pre-conceptional counselling and folic acid is recommended for all women on antiepileptic medications at $0.4 \mathrm{mg} /$ day. If family history of neural tube defect is present, recommended dose is $4 \mathrm{mg} /$ day. Monotherapy for epilepsy treatment has been associated with better fetomaternal outcomes in pregnancy. However, due to increased drug clearance in pregnancy, there is frequent need for changing of drug dosage. Lamotrigine and leviteracetam have been shown to be safest out of all the antiepileptic drugs in pregnancy in terms of fetal malformations and adverse fetal outcomes like NICU admission. Overall, generally pregnancy and delivery are well tolerated and overall neonatal outcomes are good if patient has a seizure free period before conception and epilepsy is well controlled.

Funding: No funding sources Conflict of interest: None declared

Ethical approval: The study was approved by the Institutional Ethics Committee

\section{REFERENCES}

1. Bhatia M, Adcock JE, Mackillop L. The management of pregnant women with epilepsy: a multidisciplinary collaborative approach to care. Obstet Gynaecol. 2017;19(4):279-88.

2. McPherson JA, Harper LM, Odibo AO, Roehl KA, Cahill AG. Maternal seizure disorder and risk of adverse pregnancy outcomes. Am J Obstet Gynecol. 2013;208(5):378.e1-5.

3. C. R, D. S. Prospective study of fetomaternal outcome in epilepsy in pregnancy in a tertiary care hospital. Int J Reprod Contracep Obstetr Gynecol. 2017;4:5.

4. Robinson JN, Cleary-Goldman J. Management of epilepsy and pregnancy: an obstetrical perspective. Int Rev Neurobiol. 2008;83:273-82.

5. Borgelt LM, Hart FM, Bainbridge JL. Epilepsy during pregnancy: focus on management strategies. Int $\mathrm{J}$ Womens Health. 2016;8:505-17.

6. Mari L, Placidi F, Romigi A, Tombini M, Del Bianco C, Ulivi $M$ et al. Levetiracetam, lamotrigine and carbamazepine: which monotherapy during pregnancy? Neurol Sci. 2021.

7. Coad F, Nelson-Piercy C. Neurological disease in pregnancy. Obstet Gynaecol Reprod Med. 2019;29(11):306-13.

8. Mahajan M, Pal A. Risks and management of pregnancy in women with epilepsy: a review. Int $\mathbf{J}$ 
Reprod Contracept Obstet Gynecol. 2018;7(4):128995.

9. Goel P, Devi L, Saha PK, Takkar N, Huria A, Dua D. Maternal and perinatal outcome in pregnancy with epilepsy. Internet J Gynecol Obstet. 2006;5.

10. Borthen I. Obstetrical complications in women with epilepsy. Seizure. 2015;28:32-4.

11. Deck GM, Nadkarni N, Montouris GD, Lovett A. Congenital malformations in infants exposed to antiepileptic medications in utero at Boston Medical Center from 2003 to 2010. Epilepsy Behav EB. 2015;51:166-9.
12. Chen Y-H, Chiou H-Y, Lin H-C, Lin H-L. Affect of Seizures During Gestation on Pregnancy Outcomes in Women with Epilepsy. Arch Neurol. 2009;66(8):97984.

13. Hvas CL, Henriksen TB, Ostergaard JR, Dam M. Epilepsy and pregnancy: effect of antiepileptic drugs and lifestyle on birthweight. BJOG. 2000;107(7):896902.

Cite this article as: Chithra R, Dixit SS, Janu MK, Sandhya. Fetomaternal outcomes in pregnancy complicated by epilepsy-a retrospective study. Int J Reprod Contracept Obstet Gynecol 2021;10:4536-40. 